\title{
Hierarchical structure of marine shell biomaterials: biomechanical functionalization of calcite by brachiopods
}

\author{
Wolfgang W. Schmahl*,I, Erika Griesshaber ${ }^{\mathrm{I}}$, Klemens Kelm ${ }^{\mathrm{II}}$, Andreas Goetz ${ }^{\mathrm{I}}$, Guntram Jordan ${ }^{\mathrm{I}}$, Alex Ball ${ }^{\mathrm{II}}$, Dayin Xu ${ }^{\mathrm{I}}$, \\ Casjen Merkel ${ }^{\mathrm{I}}$ and Uwe Brand ${ }^{\mathrm{IV}}$ \\ I GeoBioCenter ${ }^{\mathrm{LMU}}$ and Dept. of Earth and Environmental Sciences, LMU Munich, Germany \\ II DLR-Institut für Werkstoff-Forschung, Köln-Porz, Germany \\ III Natural History Museum London, Cromwell Road, London SW7 5BD, UK \\ ${ }^{\text {IV }}$ Dept. of Earth Sciences, Brock University, St. Catharines, Ontario, Canada
}

Received April 20, 2012; accepted September 4, 2012

Published online: October 29, 2012

\section{Biomineralization / Calcite / Texture / Raman spectroscopy / Hierarchical composite / Vital effect}

\begin{abstract}
Biologic structural materials for skeletons or teeth show a hierarchical architecture, where organic macromolecules and mineral substance form a hybrid composite material with its components inter-weaved on many length scales. On the nanostructure level brachiopods form hybrid composite mesocrystals of calcite with occluded organic molecules. On the microstructure level several types of materials are produced, on which the electron back-scatter diffraction (EBSD) technique gives insight in texture and architecture. We describe the calcite single-crystal fiber composite architecture of the secondary layer involving organic matrix membranes, the competitive-growth texture of the columnar layer and the nanostructuring of the primary layer. In the overall skeleton the organic biopolymers provide flexibility and tensile strength while the mineral provides a high elastic modulus, compressive strength, hardness and resistance to abrasion. The hierarchical composite architecture, from the nanostructure to the macroscopic level provides fracture toughness. The morphogenesis of the biomaterial as a whole and of the mineral crystals is guided by the organic matrix and most probably involves amorphous calcium carbonate (ACC) precursors. In this paper we review the hierarchical architecture of rhynchonelliform brachiopod shells, which is very distinct from mollusk nacre.
\end{abstract}

\section{Introduction}

Beyond their obvious importance for medicine and biology, biological hard tissues are also a rich source for design concepts for advanced materials (e.g. Currey 1999; Fratzl and Weinkamer, 2007) and they form the most important library of information on the evolution of life and

* Correspondence author (e-mail: wolfgang.schmahl@1rz.uni-muenchen.de) its environmental conditions. Earth scientists have been using the trace element and isotope signatures of marine shells to determine paleo sea water temperatures (e.g. Veizer et al., 1999; Buening, 2001; Brandt et al., 2003). Initially it was generally believed that the marine carbonate biominerals form in "equilibrium with sea water" (Lowenstam, 1961) such that isotope and even trace element data of fossil shell materials would be applicable to deduce water temperatures after calibration with inorganic in-vitro fractionation experiments (Lowenstam, 1961, Mucci \& Morse, 1983, Carpenter \& Lohmann, 1992). However, these chemical signatures proved to be differentiated for different organisms and for different parts of the skeleton of the same species (e.g. Auclair et al., 2003; Carpenter and Lohmann, 1995; Parkinson et al., 2005, von Allmen et al., 2010). In this paper we show by a review of nanostructural and microstructural information that mineralization of the shell is completely controlled by complex physiological processes in the organism.

Mechanical strength testing of nacre-based shell materials (Currey \& Taylor, 1974, Currey, 1977; Jackson, 1988; Barthelat \& Espinosa, 2007) showed that these natural materials have superb strength and toughness parameters. Several models have been suggested to explain strength and toughness of nacre owing to its microstructure of "mineral platelets embedded in a thin organic matrix" (Okumura \& de Gennes, 2001; Katti et al., 2005; Gao, 2006).

We turned our attention to brachiopods, a phylum of sessile marine organisms, which produce either calcitic (the Rhynchonelliformea and Craniiformea) or phosphatic (the Linguliformea) shells. Brachiopods have been populating the shallow sea floors since the Cambrian or even the late Precambrian (Williams et al., 2000). A review of the material architecture of the phosphatic shell forms has recently been published (Schmahl et al., 2008). Here we review the hierarchical architecture of the calcitic rhynchonellide forms and report some complementary observations on the subject. 


\section{Methods and materials}

The examination of a hierarchical structure involves diffraction and microscopy techniques on several length scales. Mineral phases were identified by X-ray diffraction on a GE focusing transmission diffractometer and an Oxford Diffraction area detector diffractometer operated with $\mathrm{MoK}_{\alpha 1}$-radiation. Micro Raman spectra were obtained on a confocal Raman microscope alpha 300R (WITec, Ulm, Germany). For excitation we used the second harmonic generation $(532 \mathrm{~nm})$ of an Nd: YAG laser. A $100 \times$ objective gave a lateral resolution of about $400 \mathrm{~nm}$, and a focal depth of about $1 \mu \mathrm{m}$. A sharp edge filter rejected the elastic Rayleigh scattering.

High-resolution electron imaging and diffraction were performed on a Philips CM30T transmission electron microscope equipped with a Noran EDX system and an
HPGe detector, on a LEO Gemini 1530 SEM, and a JEOL JSM-6500 SEM, and a Zeiss Ultra Plus SEM, using an accelerating voltage between 4 and $12 \mathrm{kV}$ and a beam current of $3.0 \mathrm{nA}$; electron backscatter diffraction (EBSD) was performed with the SEMs by using the HKL Channel 5 EBSD system and an acceleration voltage of $20 \mathrm{kV}$. EBSD provides crystallographic orientation information with space resolution on the sub-micrometer scale. The JPK NanoWizard ${ }^{\circledR}$ AFM system was used for observation of nanostructures in non-vacuum and wet conditions. Contact and intermittent contact modes were applied. To discriminate organic and inorganic components of the material by AFM, selective surface etching techniques were applied: the mineral component was etched with distilled water or with EDTA solution.

Samples of modern adult brachiopods were obtained from the following localities:

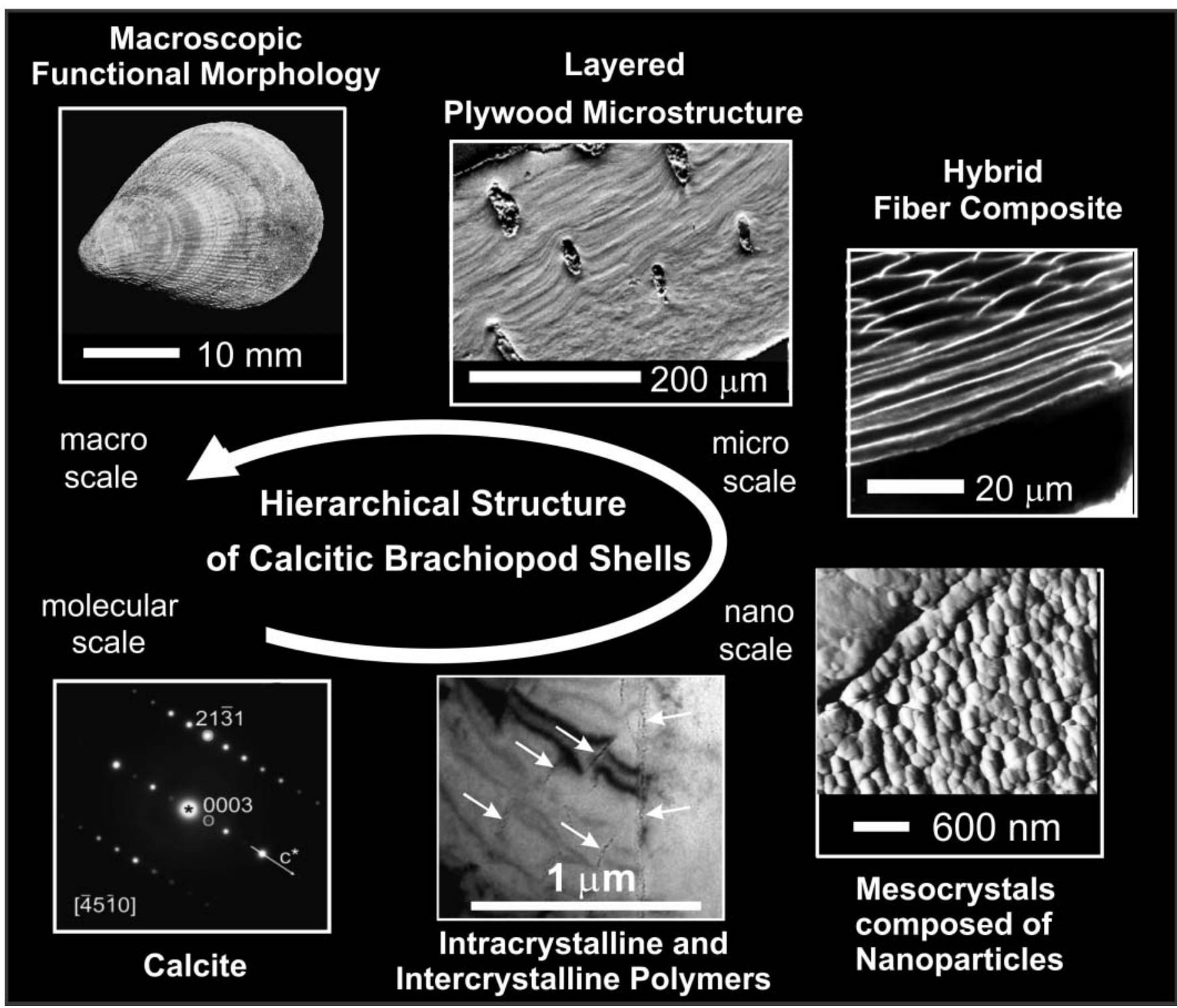

Fig. 1. Overview of the hierarchical architecture of rhynchonellid brachiopod shell material from the atomistic scale (bottom left) to the macroscale (top left). The mineral is calcite according to the diffraction pattern. Biopolymers are included in the calcite crystallites. Rod-shaped nanoparticles constituting the microscale crystals become visible with etching techniques in SEM and AFM images. These composites are termed mesocrystals accordingly. The fibrous mesocrystals are separated by biopolymer membranes which are highlighted by micro Raman spectroscopy. In the "secondary layer" of brachiopods the mesocrystals form fibers in a plywood-like structure, which consists of sublayers of different fiber direction. A nanostructured calcite primary layer forms the outer coating of the shell material. 
Table 1. Levels in the hierarchical structure of calcitic brachiopod shells.

\begin{tabular}{|c|c|}
\hline Length Scale & Feature \\
\hline Centimeters & macroscopic shape \\
\hline Centimeters-to-millimeters & $\begin{array}{l}\text { skeletal elements. e.g. valves, } \\
\text { hinge elements }\end{array}$ \\
\hline $1000-100$ micrometers & $\begin{array}{l}\text { valve main layers with different } \\
\text { microstructure: } \\
\text { (1) nano-to-micro-crystalline } \\
\text { primary layer } \\
\text { (2) fibrous layer } \\
\text { (3) columnar layer }\end{array}$ \\
\hline 500-10 micrometers & $\begin{array}{l}\text { sub-layers of main layers: } \\
\text { organized arrays of mesocrystals }\end{array}$ \\
\hline $100-1$ micrometers & fibrous or columnar mesocrystals \\
\hline $1000-10$ nanometers & $\begin{array}{l}\text { primary } \mathrm{CaCO}_{3} \text { particles or calcite } \\
\text { nano-fibrils co-oriented to form } \\
\text { mesocrystals, organic membranes, } \\
\text { and bio-macromolecules }\end{array}$ \\
\hline Molecular scale & $\begin{array}{l}\text { substances: } \mathrm{CaCO}_{3} \text {, lipids, } \\
\text { polysaccharides, polypeptides }\end{array}$ \\
\hline
\end{tabular}

Liothyrella neozelanica: collected as dead shells in a depth of about $100 \mathrm{~m}$ west of Chatham Islands (Lüter, 2008); Megerlia truncata and Gryphus vitreus: collected life in Mediterranean Sea, of the coast of Marseilles, France; Terebratulina septentrionalis: collected life in Bay of Fundy, Deer Island, New Brunswick, Canada; Notosaria nigricans: collected life at Port Pegasus, Stewart Island, New Zealand.

To stabilize the organic biopolymers present in the live shells we fixed them chemically with glutaraldehyde immediately after collecting the animals from the sea water following the procedure of Fabritius et al. (2005). The samples were left in the solution for 12 to 24 hours and they were subsequently washed repeatedly with a phosphate buffer. The samples were stored for longer time periods in the buffer. Fresh phosphate buffer is prepared every month and is exchanged monthly.

\section{Results and interpretation}

\subsection{Overview}

Biology constructs its hierarchical materials bottom-up. The description of a hierarchical structure can follow a bottom-up or a top-down approach; both outlines have their advantages and disadvantages. In a crystallographic journal, the top-down description seems more favorable to us. Nevertheless, the description will have to jump between different length scales, therefore an overview needs to be given first (Table 1, Fig. 1). Most importantly, brachiopods produce three principal calcite material fabrics which are distinct by the morphologies of the calcite: (1) densely interdigitating nanoscale dendrite-like crystallites - the so-called primary layer materials, (2) fiber composite material with fibrous calcite mesocrystals showing cross-sections in the 10 micrometer range and lengths in excess of 200 micrometers, and (3) columnar calcite composed of crystals with diameters in the 100 micrometer range and lengths reaching almost $1 \mathrm{~mm}$. The term mesocrystal has been coined (Xu et al., 2007; Gebauer et al., 2008, Meldrum \& Cölfen, 2008, Xu et al., 2008) to describe objects which are composed of nano-scale crystallites building an aggregate with a coherent 3D crystallographic lattice orientation. A direct link from the molecular (crystal structure) level to the macroscopic level is given by the crystallographic preferred orientation of the calcite mesocrystals composing the shell.

\section{Detailed description}

\subsection{Macroscopic morphology}

The macroscopic morphology of the brachiopoda is quite diverse and we refer to the rich paleontological literature on the subject (e.g. Rudwick, 1970, Williams et al., 2000). The brachiopod shells consist of two valves connected at a hinge, which is located near the umbo, an opening for the muscular pedicle by which the animal attaches to the substrate (e.g. Rudwick, 1959). Unlike bivalve mollusk shells, each of the brachiopod valves has a mirror plane (median plane) and the two valves are not mirror images of each other by a left-right symmetry as it is the case for bivalve mollusks. Brachiopods grow continuously and they continuously mineralize calcite. The mineralization occurs mainly, but not exclusively, at the commissural margin of the shell, where epithelial cells of the mantle tissue secrete the $\mathrm{CaCO}_{3}$ (Williams, 1968, Hiller, 1988, Chuang, 1996). Consequently, the commissural margin is the youngest part of the valves; the oldest part is the primary layer at the outer rim near the hinge (Fig. 2, and Griesshaber et al., 2010). A logarithmic spiral equation applies to the development of the shape of the valves as demonstrated by Rudwick (1959). The valves have quite constant thickness along their length. Juvenile individuals show thinner valves than older individuals (Griesshaber et al., 2010). Thus growth of the valve does not occur exclusively at the commissure, since mineralization is needed to increase the thickness in the posterior parts of the shell. The hinge and the umbo require permanent strengthening and reconstruction of the complex interlocking protrusions from both valves.

The brachiopod calcite shows a pronounced and systematic pattern of crystallographic preferred orientation (Schmahl et al., 2004, Griesshaber et al., 2007, Griesshaber et al., 2010), which connects the molecular scale structure with the architecture on the macroscopic scale: the [001] axes of the trigonal calcite crystals show a sharp maximum of the orientational probability density in the orientation perpendicular (or sub-perpendicular) to the shell vault (Schmahl et al., 2004, Griesshaber et al., 2007, Fig. 2a).

\subsection{The main shell layering with up to three distinct calcite microstructures}

Depending on the species, modern brachiopod shell valves usually consist of two or three distinct layers of different material microstructures (details to be described in the sec- 

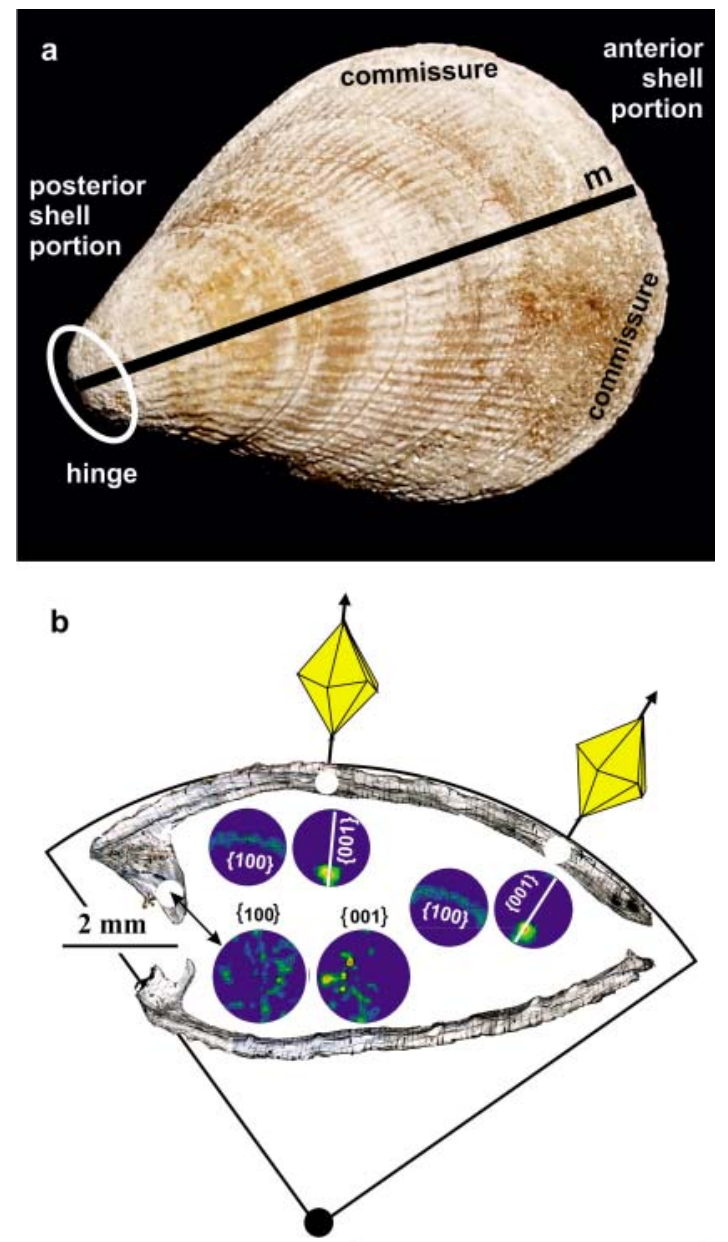

Fig. 2. (a) Photograph of the ventral valve of the modern brachiopod Terebratulina septentrionalis. The black line indicates the median plane through which cross-sections were cut for SEM and EBSD analyses. (b) Cross section through the median plane of the valves of Megerlia truncata and pole figures for the calcite $\{100\}$ and $\{001\}$ plane normals as determined by EBSD at the indicated locations in the shell cross section. Brachiopod shell calcite $c$-axes are typically parallel to the radius of curvature of the shell (Schmahl et al. 2004, Griesshaber et al., 2007). Both valves show a sharp uni-axial fiber texture. Near the hinge, i.e. in older parts of the shell a bimodal or even multi-modal distribution pattern of $\{001\}$-poles is present (Griesshaber et al. 2007).

tions below): (i) nanostructured outer primary layer, (ii) columnar layer (iii) fibrous layer. The outside of the shell is always covered by a thin organic membrane, the periostracum. For all calcitic brachiopods the outermost (primary) layer of the valve is formed by the nano-structured primary layer material (Fig. 3). For Liothyrella neozelanica (Goetz et al., 2009) the columnar layer follows inward below the primary layer, and the fibrous and the columnar layer change their thickness along the length of the valve in a wedge-like manner as one layer replaces the other essentially preserving the thickness of the valve. Occasional interlayering of fibrous material into columnar material can be observed in L. neozelanica (Goetz et al., 2009).

The thickness of the layers depends on species: the nanostructured outer layer is usually 50-100 micrometers thick, the fibrous layer can reach some hundreds of micrometers, and the columnar layer may be absent or can reach one millimeter, respectively.

\subsection{Main layer level - Fiber packing and fiber sub-layers, column packing}

\subsubsection{Columnar main layer}

Not all rhynchonellide brachiopod families possess a columnar layer. Figure 3 shows EBSD maps of the columnar layer of Liothyrella neozelanica (Goetz et al., 2009). From the contact zone of the columnar layer and the primary layer towards the inside of the shell the column width increases and the axial crystallographic preferred orientation becomes increasingly sharp; it even reaches a three-dimensional single-crystal-like texture (Fig. 3) which is not uncommon in biocalcite (Schmahl et al., 2012). Both these observations suggest that the columns form by a competitive growth mechanism starting at the contact between columnar and primary layer as the plane of nucleation. Assuming that the triad axis [001] of calcite is the fastest direction of growth, crystals with [001] parallel to the main growth direction of the shell will extend their size as long as $\mathrm{Ca}^{2+}$ and carbonate are added, while the growth of other crystals with [001] more parallel to the plane of nucleation is impeded by their neighbors and their growth will stop. Texture and microstructure formation by competitive growth has been described for the calcite of the avian egg shell (Rodriguez-Navarro \& Garcia-Ruiz, 2000; Dalbeck \& Cusack, 2006).

\subsubsection{Fibrous main layer material}

The fibrous layer usually forms sub-layers between which the fiber direction varies. In each sublayer the mesocrystal fibers are stacked in parallel to form a characteristic interlocking microstructure (Fig. 4). Figure 5a and b show EBSD maps of the crystal orientation in such fiber packings - two sub-layers can be seen containing fibers sectioned in different orientation: longitudinal and transverse. Thus a plywood-like structure is formed.

\subsubsection{Primary main layer material}

Careful inspection of Figs. 5a and 6a shows that the primary layer is differentiated into sub-layers, where usually nanostructured material is on the outside, while micrometer-sized columnar or platelet-shaped crystals form a sub-layer towards the inward of the valve (e.g. Schmahl et al. 2008; Goetz et al. 2009, Griesshaber et al. 2010).

\subsection{Microstructure level: mesocrystals, columns, fibers, dendrites}

\subsubsection{Columnar layer material}

The large and mineralogically inconspicuous calcite columns (Fig. 3) forming the building units of the columnar layer at the microscale have their calcite $c$-axis parallel to the column axis, while the column is more or less perpendicular to the shell surface. In contrast to the fibrous and the primary layer material we have so far not detected nanostructural features inside the crystals. A "surface lamination" on the submicrometer scale is visible in SEM micrographs of fractured samples (Schmahl et al., 2010), but it is impossible to exclude that this feature is due to $\{104\}$ cleavage faceting. 


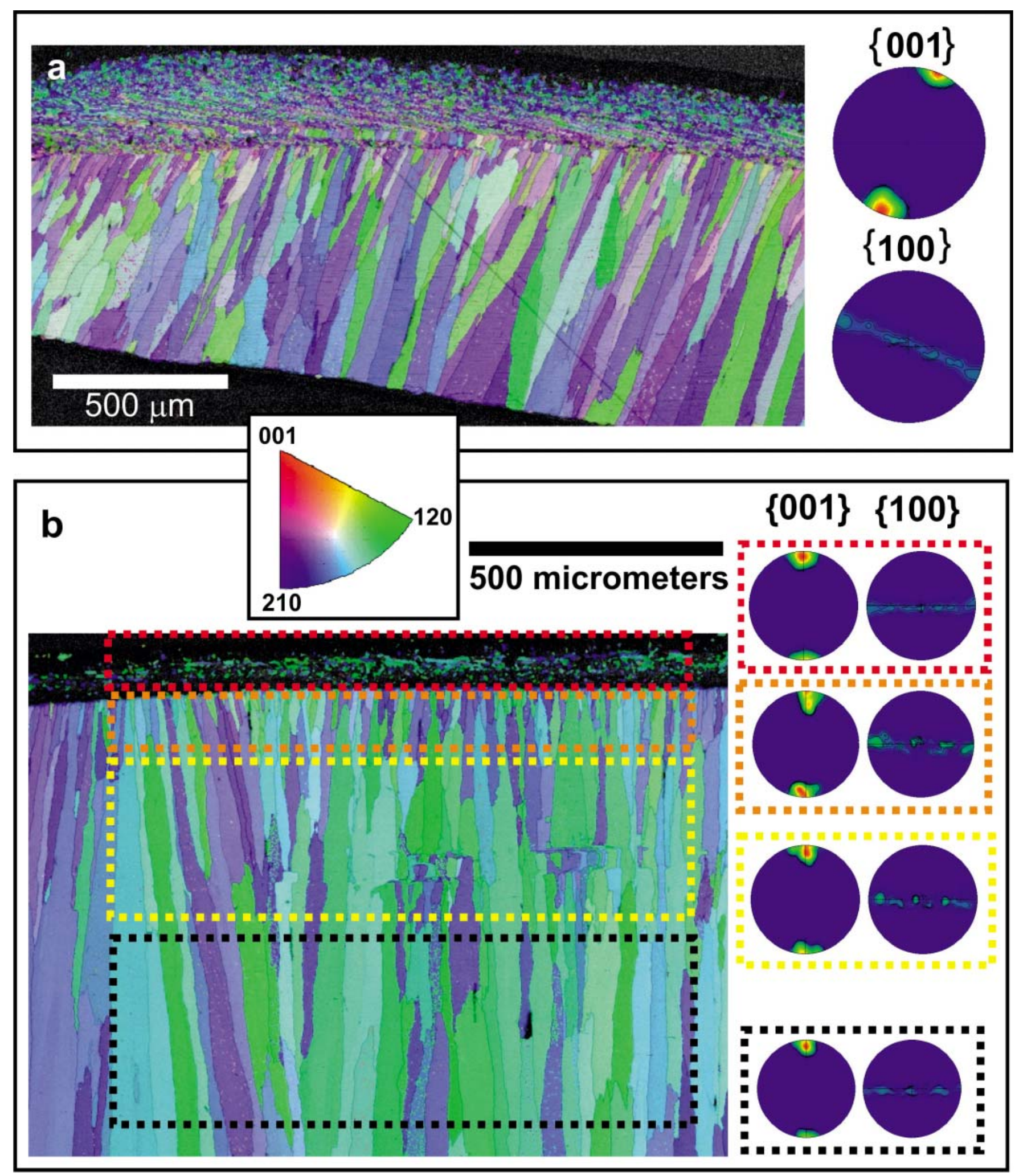

Fig. 3. EBSD maps of the primary and the columnar layers of Liothyrella neozelanica and corresponding pole density figures. The nano-structuring of the primary layer prevents complete EBSD pattern indexing due to several crystal orientations superimposed in the EBSD patterns. Note the $c$-axis aligned calcite columns and sharp cylindrical textures which are qualitatively identical for the columnar layer and the fine-grained primary layer. The EBSD maps are given in inverse pole figure colors (see insert for color scale). Rectangular color frames indicate selected areas for which pole density figures are shown in a frame with corresponding color. The columnar crystals widen successively from their apparent nucleation point at the interface with the primary layer towards the inside of the shell. Similarly the texture sharpens-up successively in the same direction, and there is even a tendency to a 3 dimensional single-crystal-like texture in the innermost part of the columnar layer (bottom right pole figure). 


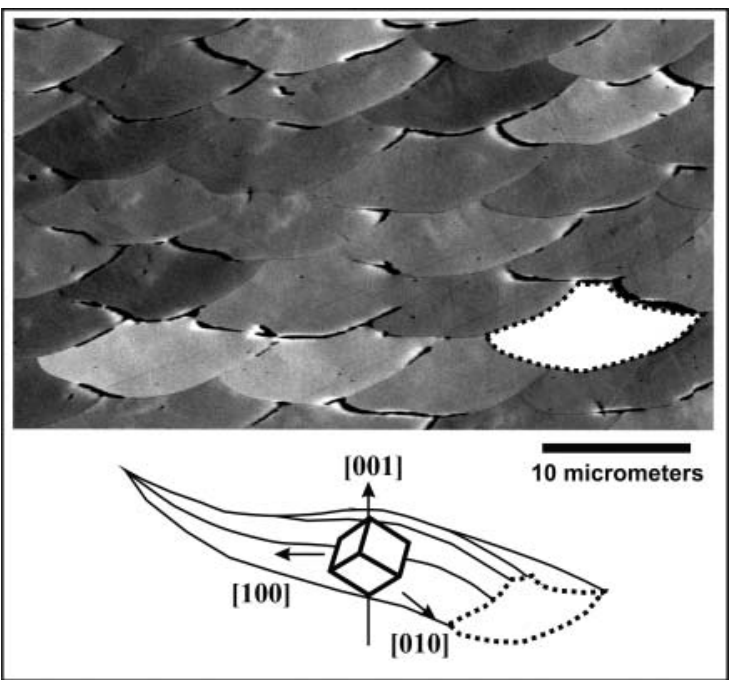

Fig. 4. Cross section through an array of fibrous calcite crystals of Megerlia truncata (SEM, forward scattered electron contrast). Note the characteristic interlocking of convex and concave sides of the fibers. A typical fiber would reach a length of some hundreds of micrometers. The sketch in the insert indicates the typical crystallographic orientation of lattice and nominal $\{104\}$ cleavage planes with $c$-axis perpendicular to the fiber and morphological fiber axis in the $a$-b-plane (see Fig. 5).

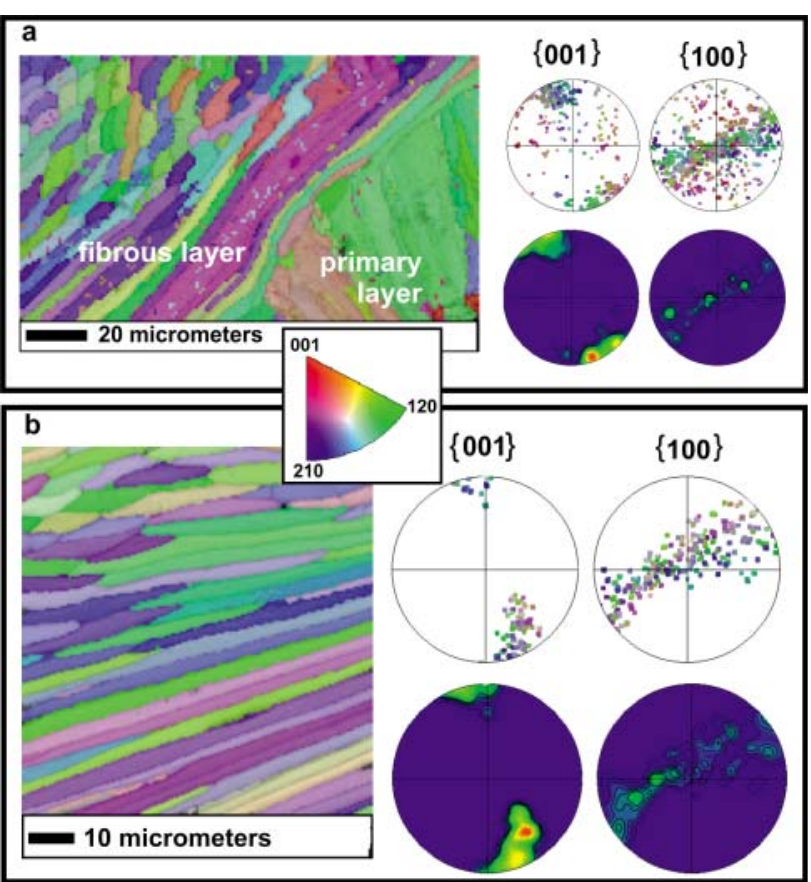

Fig. 5. EBSD maps showing the crystallographic orientation of the biocalcite constituting the primary layer and the fibrous secondary layers of the brachiopod Terebratulina septentrionalis in inverse pole figure coloring as indicated in the insert between (a) and (b). Fibers are seen cut both in longitudinal and in transverse directions. Note that uniform coloring indicates uniform orientation of the crystal lattice as in a single crystal. The adjacent pole figures (stereographic projections of the reciprocal lattice axes) use the same color scheme. Note that the textures of primary and fibrous layers are qualitatively similar. In this part of Terebratulina septentrionalis we see a strong tendency to a three-dimensional single-crystal like texture rather than a simple cylindrical texture.
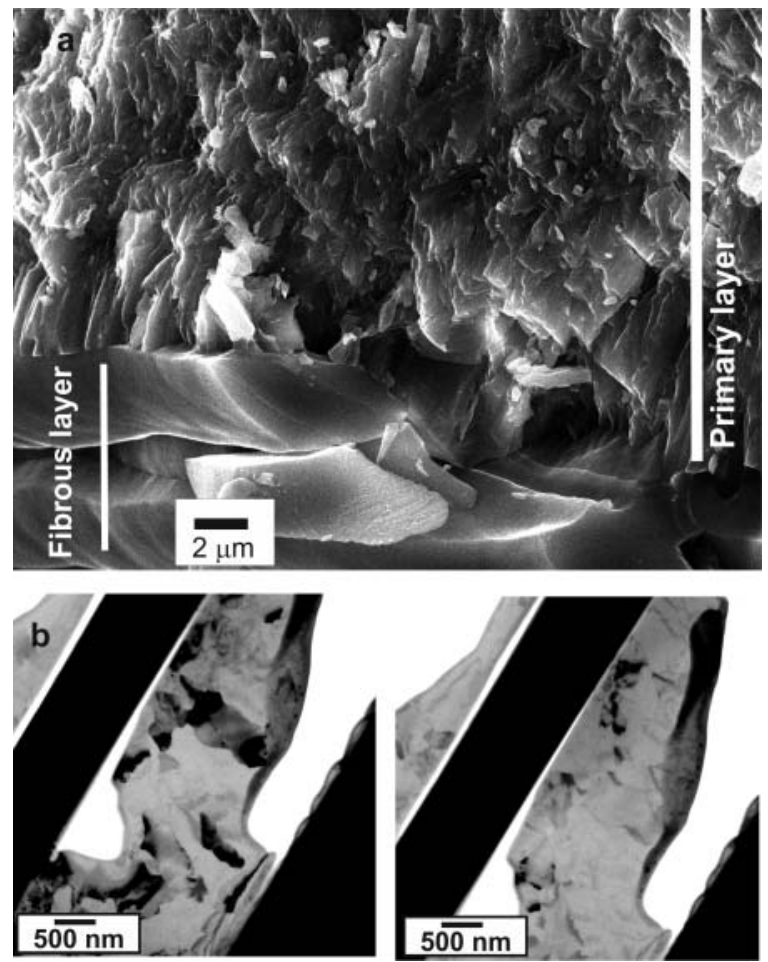

Fig. 6. (a) SEM micrograph of a fracture surface through the nanostructured calcite of the primary layer and the immediately adjacent fibrous layer of Megerlia truncata. (b) TEM images taken at different tilt angles of a FIB section of the primary layer of Megerlia truncata highlighting the individual crystallites and their interlocking fabric.

These crystals appear much like inorganic crystals. From isotope and trace-element investigations von Allmen et al. (2010) conclude that the columnar calcite layer is geochemically closest to inorganic calcite for all brachiopod calcites.

\subsubsection{Fibrous main layer material}

Calcite mesocrystal fibers with internally uniform crystallographic orientation (within the $\pm 0.3^{\circ}$ resolution of the EBSD technique) form the fundamental unit at the micro scale. The shape of such a mesocrystal fiber is sketched in Fig. 4. We observed fiber lengths up to 200 micrometers, and the width is typically in the range of 2-20 micrometers. Micro Raman spectroscopy (Fig. 7) is able to demonstrate that the fibers are sheathed by an organic membrane. At the interfaces between the fibers (Fig. 7) the fluorescence background signal is significantly enhanced compared to the inside of the crystals. The membrane is continuous as usually there is no transmission of crystallographic orientation between neighboring calcite fibers. EBSD shows that the crystallographic $c$-axis (triad axis) of each calcite mesocrystal fiber is perpendicular to the morphological axis of the fiber (Fig. 5, and Schmahl et al., 2004, Griesshaber et al., 2007, Griesshaber et al., 2010), while the morphological axis of the fiber can be in any direction in (or nearly in) the crystallographic (001) plane (Figs. 4, 5). Between neighboring morphologically parallel fibers the c-axis direction is (nearly) constant, while the aand b-axes change orientation. As the fibers are curved, the morphological axis changes its crystallographic direction within a given fiber (while the crystallographic lattice orientation remains constant). 

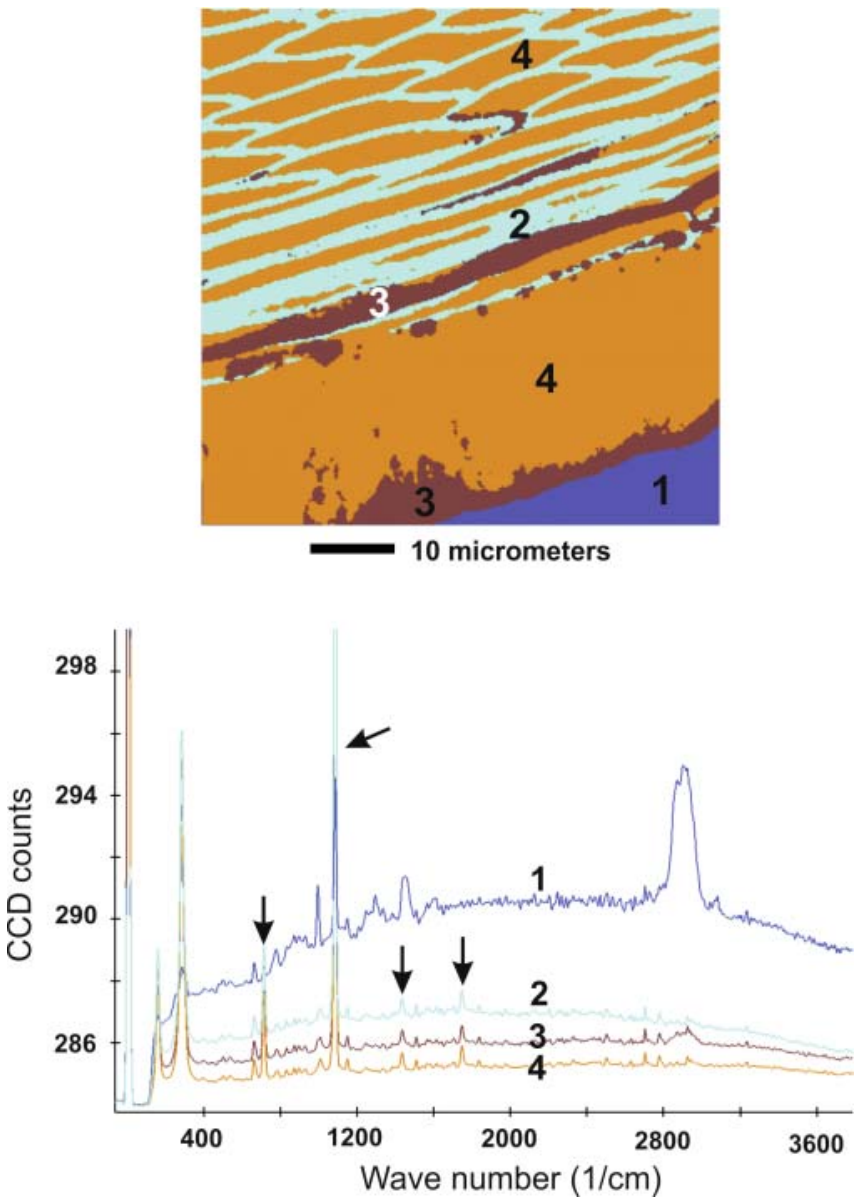

Fig. 7. Raman microprobe map highlighting the organic membranes surrounding the calcite fibers and the typical spectra on which the map colors are based. From top to bottom: (1) Epoxy material embedding the mount, (2) spectra obtained at the boundaries of the fibers, note the increased fluorescence and the absence of the epoxy bands near $2900 \mathrm{~cm}^{-1}$, (3) spectra obtained at the surface near the primary layer and a the contact primary/secondary layer giving a signal of epoxy which has penetrated the sample, (4) calcitic parts of the shell. The Raman peaks expected for calcite are indicated with arrows.

\subsubsection{Primary layer material}

In the primary main layer micro-sized crystals are frequently found in a layer adjacent to the fibrous layer. These coarser crystals look like a miniature form of the columnar calcite and may well represent the nucleation stage of the competitive growth mechanism building the columnar layer (see the lengthy crystals of the primary layer in Figs. 5a and $6 a$ with $c$-axis parallel to their length).

\subsection{Nanostructure level}

\subsubsection{Fibrous main layer material}

Careful selective etching of calcite and observations with AFM and SEM reveal the internal structure of the calcite mesocrystals and what we address as the constituting primary particles. Figure 8 shows two images obtained with AFM by in-situ etching into a polished surface of the fibrous calcite layer of two different brachiopod species. The etching of the calcite leaves the biopolymer membranes behind which separate each of the three micro-scale calcite

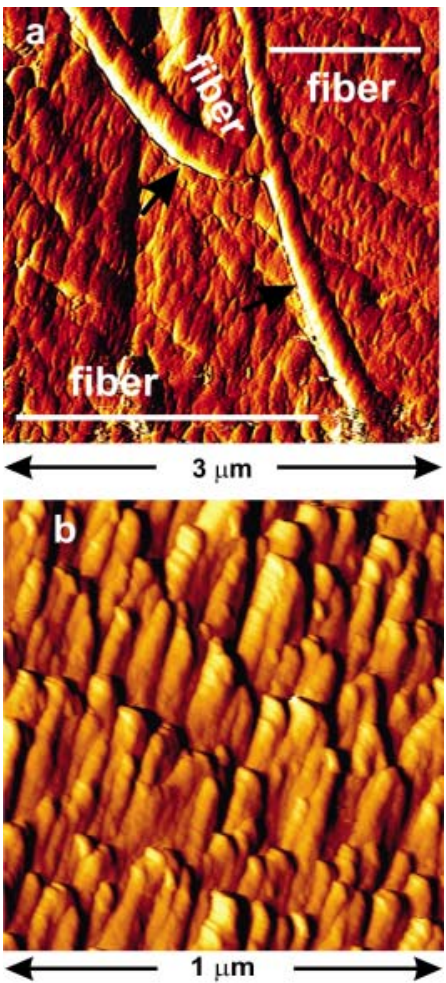

Fig. 8. AFM images of the internal mesocrystal architecture inside micro-scale calcite fibers from the valves of Terebratulina septentrionalis (top) and Gryphus vitreus (bottom). These structures are revealed by etching a polished section of calcite with distilled water or with EDTA solution. Etching removes the surface layers of the calcite and such that the organic sheaths around the microscale fibrous crystals protrude from the surface of the sample (black arrows in top image). The etching also reveals nano-particles or nano-fibrils that constitute the micro-scale fibrous crystals as mesocrystals.

fiber units present in the imaged area (Fig. 8a, Terebratulina septentrionalis). The membranes protrude from the surface and are indicated by black arrows. Also, the mesocrystal architecture of the fibrous biocalcite crystals is revealed as elongated nanoparticles become visible. Further, these nanoparticles are arranged in nano-scale lamellae. For Gryphus vitreus (Fig. 8b) we see nanofibrils which appear to be subdivided into smaller nanoparticles. The nanofibrils and nanoparticles composing the micro-scale units form a crystallographically co-oriented lattice (see description of the micro-scale levels in Section 4.). The patterns observable by SEM on fracture surfaces (Fig. 9) also highlight the mesocrystalline constitution of the calcite mesocrystal fibers. First, the fibrous calcite shows conchoidal fracture (Fig. 9a) - it does not cleave perfectly flat like its abiotic counterpart. The nano-fibrils form a lawn of nano-scale protrusions on some of the visible surfaces (Fig. 9b). In fractures cutting transverse across fibers (Fig. 9c) an internal nanostructure is visible between the remnants of the biopolymer membranes. Figure 10 displays high-resolution SEM micrograph of the mesocrystal fibers of the brachiopod Notosaria nigricans. Here triangular shapes of the nanoparticles appear to be frequent. Cusack et al. (2008) showed AFM pictures of shell material of Terebratulina retusa where triangular nano-scale features could be seen pointing all more or less in a parallel direction. Cusack et al. addressed these features as the primary particles. We did not find such triangular shapes in our very careful 


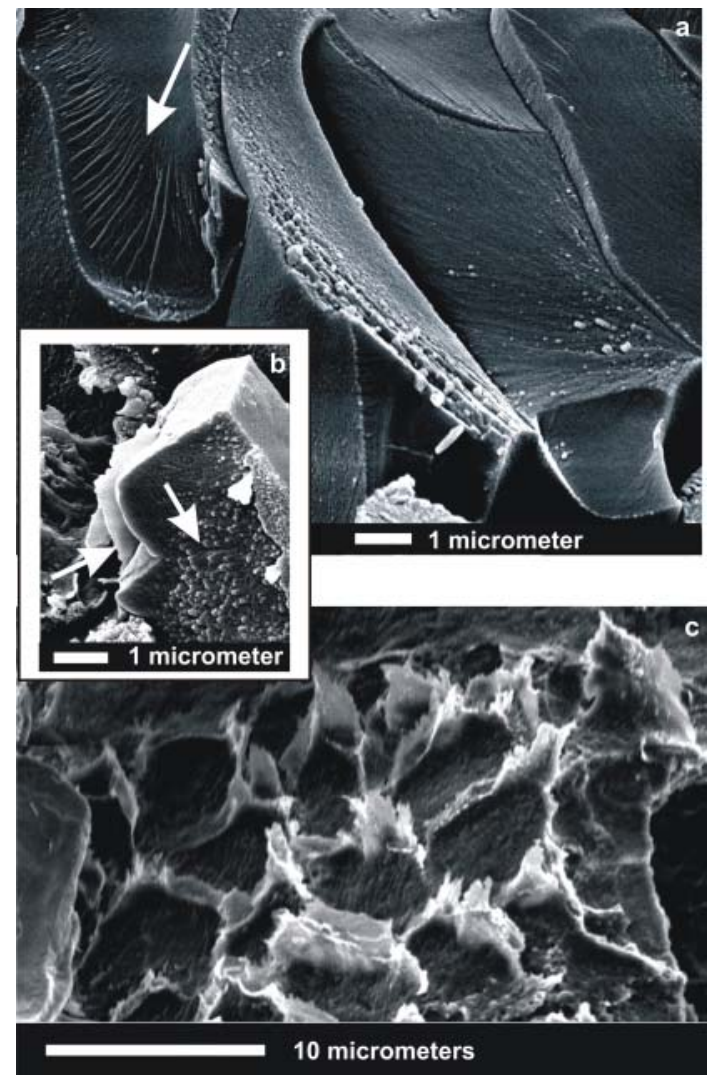

Fig. 9. SEM images of fracture surfaces of the fibrous layer of the species Terebratulina septentrionalis. The bio-macromolecules in the shell material were fixed chemically directly after removing the animal from the sea water. Note the conchoidal fracture of the material (a). Arrows in the small inserted figure (b) mark a remnant of the organic sheath around a fiber and nano-fibrils which can be seen protruding from the surface. In (c) the fracture went transverse across the fibers. Note the remnants of the ripped organic sheaths around the fibrous calcite mesocrystals.

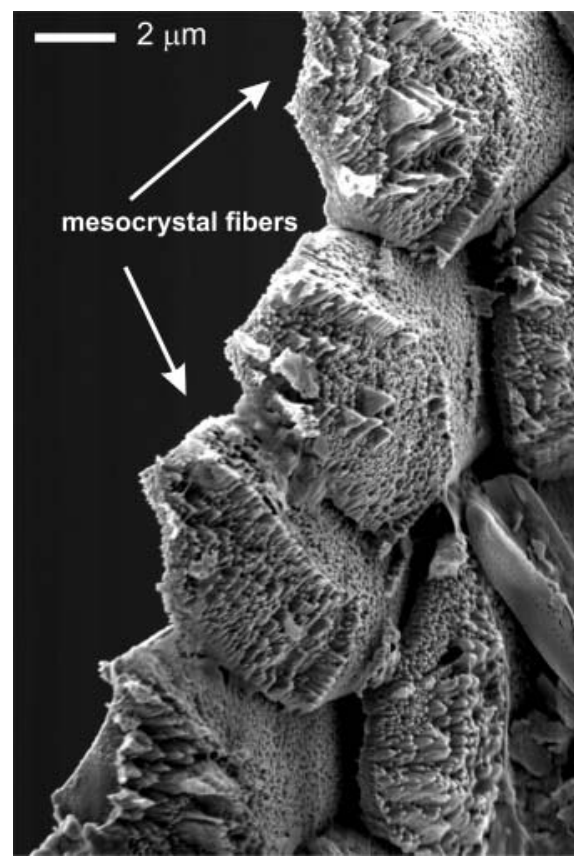

Fig. 10. High-resolution SEM micrographs demonstrating the mesocrystalline constitution of the calcite fibers of the brachiopod Notosaria nigricans. In this specimen the organic matrix was not fixed.

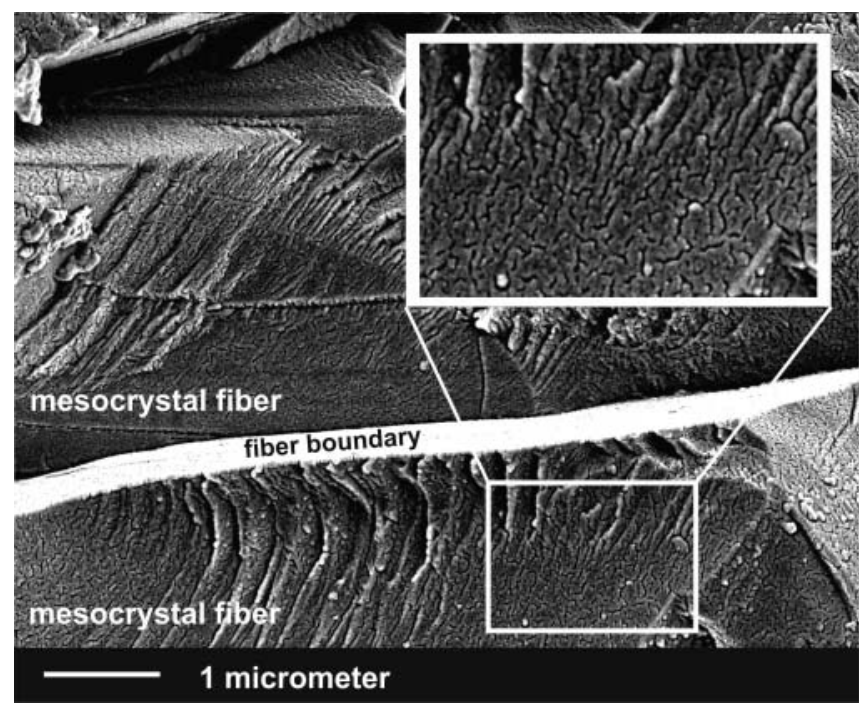

Fig. 11. The internal mesostructure of micro-scale biocalcite crystal fibers of T. septentrionalis becomes visible in high-resolution SEM. Irregularly shaped voids appear as black contrasts. These voids form as the organic macromolecules inside the fibers decompose in SEM conditions at the electron-bombarded surface. The white arrow shows conchoidal fracture features of the fibrous biocalcite. The terrace formed at the location of the organic sheath lining the imaged biocalcite fiber shows a strong white contrast (labeled as "fiber boundary" in the image).

AFM studies of Terebratulina septentrionalis. Just like Cusack et al. (2008) we used the common triangular pyramidal AFM sensors and we made sure to replace broken or worn-out tips which tend to produce triangular image features due to convolution of the sensor-tip with the real surface morphology. More work is needed to shed light on the biodiversity of calcite primary particles in rhynchonellide brachiopods.

We attribute the nano-fibril and nano-particle constitution of the mesocrystals to the extremely thin organic membrane molecules which are only visible in TEM (Fig. 12). Those molecules do not appear to form membranes which completely encapsulate nano-compartments, but they appear to be disrupted, allowing the calcite around them to form a coherent or semicoherent crystal lattice. This lattice terminates at the larger and stronger membranes which can be seen separating the micro-scale fibers in Figs. 7, 8a and 9c.

If the membranes are fixed in-situ chemically they obtain increased tensile strength and stick out of fracture surfaces like tattered cloth (Fig. 9c). More observations on the internal nanostructure of fibrous calcite are shown in Schmahl et al. (2012) in the context of a discussion of systematic features of calcite biocrystals.

\subsubsection{Primary main layer material}

The outer primary layer material is structured on the scale of hundreds of nanometers with interdigitating dendrite-like mesocrystal grains (Fig. 6 and Goetz et al., 2011, Schmahl et al., 2011). So far neither in SEM nor TEM observations we were able to detect organic components within or around the grains of the primary layer. However, for the transport of the calcium carbonate in place and for the control of formation of the interlocked 

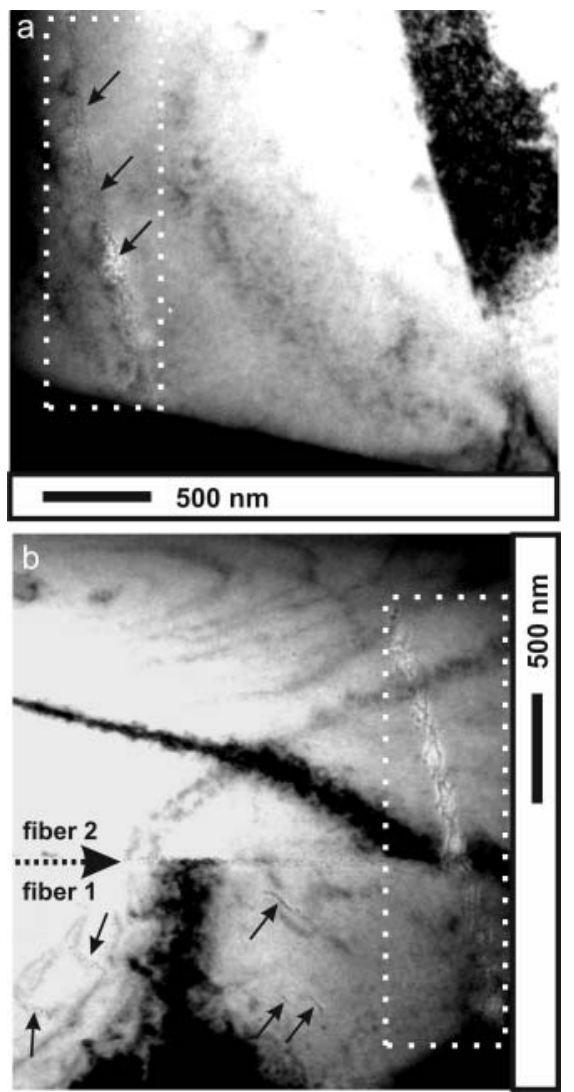

Fig. 12. (a) TEM micrographs of a FIB-section through the fibrous layer of Megerlia truncata. The continuous and gently curved dark stripes in the TEM images are bend contours. The contrasts from the ubiquitous intra-crystalline organic macromolecules are indicated by black arrows. Two large bio-macromolecules are highlighted by the white dotted frames. The dotted arrow in (b) indicates a bio-macromolecule membrane separating two calcite fibers.

nanostructure we assume that biologic membranes at least must have existed at some stage. They may be too thin to be visible in TEM (we were not able to achieve atomic resolution due to beam damage on the calcite). If there are organics in the primary layer they are much less abundant than in the fibrous layers and they are of a different kind.
The interlocked nano-scale structure of the primary layer material leads to a high hardness in micro-scale Vickers indents, up to twice as high as geologic calcite crystals (Griesshaber et al., 2007, Schmahl et al., 2008). By comparison, for the fibrous layer, micro-scale indents which are larger than the fiber diameter, we measured hardness values equal to or less than that of geologic calcite due to delamination of the fibers at the organic sheaths around the fibers.

\subsection{Molecular level}

\subsubsection{The role of intra-crystalline organics and amorphous precursors}

For calcitic brachiopods, about $98 \%$ of the shell is calcite albeit with absolutely non-classical mineral morphology. The remainder is organic material. The presence of organic macromolecules within the calcite crystals can be seen in the transmission electron microscope (Fig. 12) as contrasts that appear to have some crystallographic orientation (Schmahl et al., 2008, Griesshaber et al., 2009). It is still a matter of debate and research, how the $\mathrm{CaCO}_{3}$ is transported to and deposited at the location where it is finally found in the shell material. Williams (1968) claims to have observed vesicles filled with $\mathrm{CaCO}_{3}$ in the cells of the mantle epithelium. These vesicles would then be exocytosed and attached to the mineral forming the shell. This very plausible suggestion is consistent with our observation of the mesocrystalline architecture (Figs. 8, 9, $10,11)$ but it nevertheless needs corroboration by modern studies.

By TEM we observed in a modern brachiopod shell a large compartment in the typical size and shape of a micro-scale brachiopod calcite fiber which did not give a sharp diffraction pattern but only a diffuse isotropic halo. We thus concluded that the compartment consisted of amorphous calcium carbonate (ACC, Fig. 13). Under TEM conditions (electron irradiation, UHV) the ACC in this compartment crystallized to form an aggregate of calcite and vaterite crystallites (Fig. 13, and Griesshaber et al.,
Fig. 13. In-situ crystallization of ACC compartments of the brachiopod $M e$ gerlia truncata in the TEM. The compartments are the typically-shaped cartridges formed by the biopolymer sheaths around brachiopod calcite fibers. The ACC gives a bright contrast in these images and can be recognized by the absence of a diffraction pattern (not shown). The calcite crystals show diffraction patterns such as shown in Fig. 1. (a) shows the ACC compartment shortly after the start of the crystallization where nucleation occurs at the site of the organic sheath. In (b) the in-situ crystallization has consumed the ACC. In (c) an intermediate state is shown at a different location in the material.
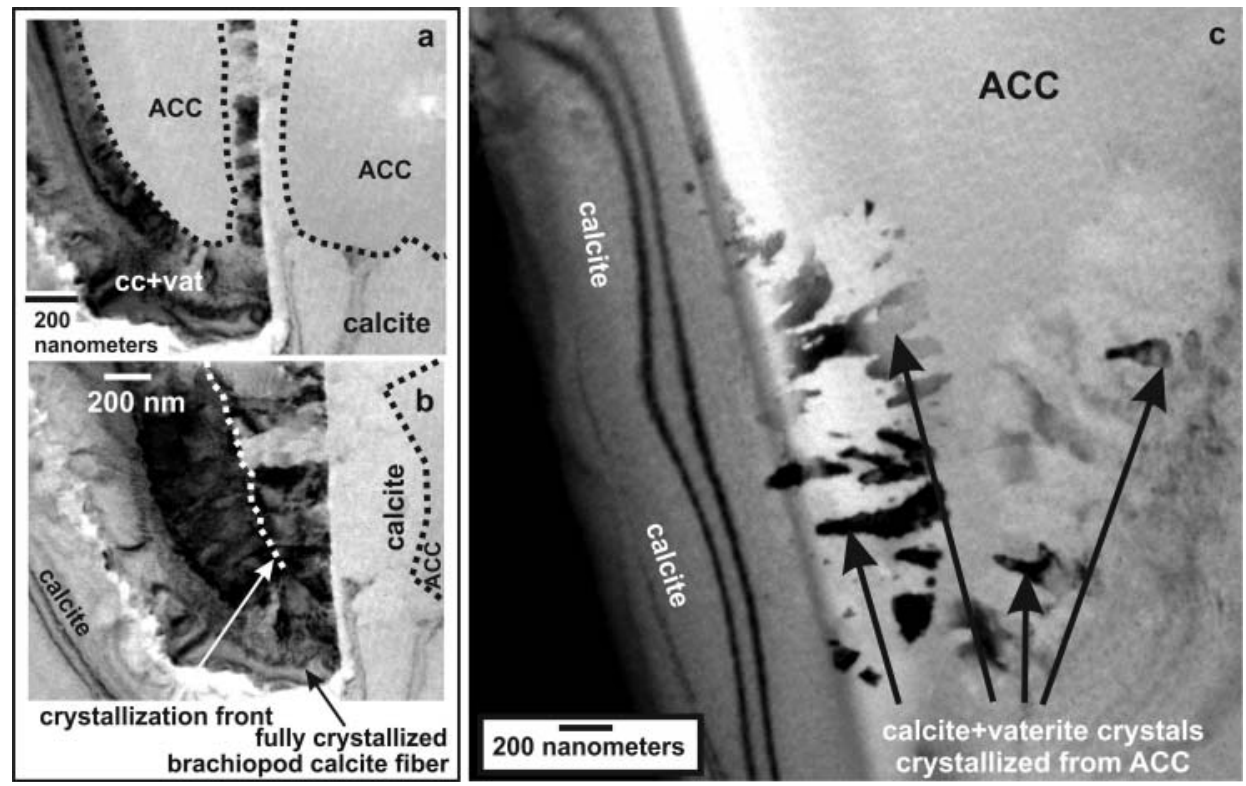
2009). The ACC compartment was located near a defect of the shell which had been repaired by the animal when it was still alive. This observation suggests that at the onset of brachiopod shell formation the first-formed material is ACC, which then crystallizes into one of the crystalline $\mathrm{CaCO}_{3}$ polymorphs, depending on the organism in question. This scenario explains that organic molecules are occluded in the $\mathrm{CaCO}_{3}$. These are remnants from vesicle walls and/or molecules preventing premature crystallization of the ACC.

Pokroy et al. (2006) have shown for many carbonates of biologic origin, that heating of the material to $200{ }^{\circ} \mathrm{C}$ results in a relaxation of the lattice parameters of the carbonate mineral, such that it is likely that the intra-crystalline organics strain the lattice, and the strain is released upon the decomposition of the biomolecules on heating. A recent accurate study of Gaspard et al. (2008) has shed some light on the molecular constitution of the organic material in the shell, but the substance remains enigmatic owing to its complexity. Three major types of macromolecules are typically considered as relevant in biominerals: (i) phospholipids, which are the fundamental molecules composing biological cell membranes and vesicle membranes, (ii) polysaccharides, where chitin is the most abundant form used as a structural material by animals (AlSawalmih et al., 2008, Fabritius et al., 2009), and (iii) proteins, which are ubiquitous in all tissues, controlling functions (e.g. morphogenesis, Ca- and proton pumping, etc.) as well as strength (e.g. collagen in bone, Currey, 2006). According to Gaspard et al. (2008) relatively high amounts of glucosamine may suggest the presence of chitin in the shell matrix of the investigated rhynchonelliform brachiopods, while the group found several different proteins of $20-25 \mathrm{kDa}, 37 \mathrm{kDa}$, and $50 \mathrm{kDa}$ in different species as well as low molecular weight glycoproteins. Cusack et al. (2000) had reported a $62 \mathrm{kDa}$ glycosylated protein.

\section{Discussion}

\subsection{What is the evolutionary advantage of the hierarchical structure?}

Calcium and carbonate are abundant components of sea water, thus calcite is easily available to marine organisms. Yet - calcite is also extremely brittle as a pure mineral and useless as a structural material, unless it is biomechanically functionalized as a composite with adequate mechanical performance. Organisms produce their materials in a bottom-up process from the level of cells which secrete the substances which finally constitute the skeleton or tooth. The morphogenesis is controlled via organic membranes, which compartmentalize space. This principle applies on all length scales from the nanoscale liposome membranes of vesicles inside the cells via the cell walls to macroscale connective tissue, cutis, or dermis (Alberts et al., 2008). Thus a hierarchical architecture is common to all biological structures, including mineralized tissue such as skeletons and teeth, where the membranes and the mineral form a hybrid composite. The compartments formed by the organic matrix appear to be filled initially with an amorphous mineral precursor, which has no specific demand on shape and can be molded into any morphology (Addadi et al., 2003); it is turned into calcite insitu in a second stage (Griesshaber et al., 2009, Weiner and Addadi, 2011, Goetz et al., 2011). To stabilize the $\mathrm{CaCO}_{3}$ precursor in an amorphous state at least temporarily, specific organic additives or matrix are used as shown in very good detail by Fabritius and Ziegler, 2003, Fabritius et al., 2005, Ziegler et al., 2005, for crustacea. The high solubility of ACC is also of advantage to create a finally dense solid mineral product which needs filling up of voids between primary particles during or before crystallization of the mineralized tissue. In the crystallization step the organic components become at least partially occluded in the crystals and they can also be partially pushed ahead of the crystallization front and accumulate at the thick organic sheaths of the mesocrystals. The hierarchical hybrid composite architecture is thus a straightforward result of the general biologic morphogenetic process. Even the biogenic formation of composite crystals, i.e. millimeter-scale single-crystal-like co-oriented mineralized hybrid composites of membrane-lined mesocrystals seems to be not uncommon by this process (Griesshaber et al., 2012, Schmahl et al., 2012).

With this architecture the biocalcite is very distinct from inorganic calcite. Only the gross chemical composition $\mathrm{CaCO}_{3}$ and the molecular level crystal structure are in common. An obvious distinguishing feature in the resulting properties is the absence of $\{104\}$ cleavage (Fig. 9) and the increased hardness of the biocalcite (Schmahl et al., 2008, Merkel et al., 2009) compared to abiotic calcite.

Just like an unfunctionalized pure mineral is biomechanically unsuitable, a skeleton, tooth or shell structure based on organic molecules alone has disadvantages. In the composite material, the mineral contributes its high elastic modulus (stiffness) which improves the efficiency of biomechanical loading frames for the amplification of muscle action. The mineral further provides compressive strength, bending strength, hardness, and abrasion resistance to the composite. Due to the oversaturation of sea water with respect to calcite, the chemical components of $\mathrm{CaCO}_{3}$ are easily available for marine organisms to form voluminous devices, if necessary. The organic component of the hybrid composite mineralized tissue provides morphogenetic control, tensile strength, flexibility, and, to a certain degree, ductility. It is important to note that the composite is more than the sum of its parts. One effect of the biomolecules occluded in the calcite crystals is the inhibition of dislocation motion. Thus the "soft" component increases component increases the hardness probed by a nano-scale indent by a factor of two compared to inorganic calcite single crystals (Griesshaber et al., 2007; Schmahl et al., 2008; Merkel et al., 2009). Dislocation motion is also the cause of the $\{104\}$ cleavage of calcite and this is also inhibited by the macromolecules inside the calcite. The organic molecules between the calcite fibers form a flexible adhesive matrix. This feature makes the biomaterial softer to micro-scale indents as the fibrous hybrid composite can tolerate a certain degree of deformation by dislodging of the fibers without the brittle failure 
which would occur in pure calcite. Further, if a crack develops under stress, both the mesocrystal architecture and the fiber composite architecture divert and break up the crack into many subcracks on their respective length scales. These processes consume the energy of the crack and avoid critical stress concentrations at the crack tips. With cracks thus effectively blunted the fracture toughness of the material is increased. In fibrous layers of brachiopod shells the fibers are parallel to the shell surface. In this way any cracks are channeled to propagate parallel to the shell rather than perpendicular to it. Thus extensive crack propagation is required before the shell can fail completely and the organism may have a chance to survive and repair the damage.

The composite material architecture allows for adaptation of the material properties using the same basic constituents and structural recipes for material construction. This "engineering" principle is used in the main shell layering. A brittle shell would hardly provide an evolutionary advantage for the organism unless strength is achieved by thickness (as in the shells with columnar layers).

A toughened hybrid composite shell material, on the other hand, contains a substantial and biologically expensive organic component. This makes it prone to enzymatic attack by bacteria or predators. A suitable coating is necessary. In the outer, primary layer of brachiopod shells there are no large inter-crystalline organic membranes (Goetz et al., 2011). The interdigitating nano-scale grain fabric of this layer (Goetz et al., 2011) provides a high hardness and stiffness but this also makes the material brittle (Griesshaber et al., 2007, Schmahl et al., 2008). The main layering of the brachiopod shell thus offers a biomechanical advantage: The resistive, hard protective cap formed by the primary layer is constructed as a thin surface sheet, while the bulk of the shell of twolayered brachiopods is built from the more ductile and tough fiber-composite material. If the shell valves flex under an applied load, a thin brittle layer is less likely to break or chip-off than a thicker brittle layer. (The bending stresses in a solid layer are proportional to thickness, Currey, 2006). This design principle is found in a much more sophisticated structure in the shell of the phosphatic brachiopod Lingula anatina (Merkel et al., 2009), where thin mineralized layers alternate with purely organic layers in a laminate. The design principle of a thin hard cap on a ductile base is used e.g. in our teeth (hard enamel on dentine, Currey, 1996) and in protective armor technology. Both in biology and technology, the plywood-like arrangement of sublayers of the fibrous layer are a common measure to improve material strength and toughness in hierarchical fiber composites. They are found in vertebrate bone (Weiner et al., 1999), lingulid brachiopods (Schmahl et al., 2008, Merkel et al., 2009), and in the cross-laminated layer of mollusks (Kamat et al., 2000).

In view of the sophisticated and biodiverse architecture of biocalcite materials, which is evidently controlled completely by complex physiologic processes, the geochemical working hypothesis of a "formation in equilibrium with sea water" should be given up as a base for any considerations. If any brachiopod calcite material can be likened to inorganic calcite it is the columnar layer material (van Allmen et al., 2010).

Acknowledgements. We are grateful to E. Kessler, T. Westphal, D. Dettmer and R. Enders for the skilful preparation of samples. We would like to thank A. Bitner, Warszawa, Poland, C. Lüter, Berlin, Germany, and N. Hiller, Christchurch, New Zealand, for brachiopod samples, and A. Ziegler, Ulm, for continuous advice. Financial support by the German Research Council (DFG) is gratefully acknowledged.

\section{References}

L. Addadi, S. Raz, S. Weiner, Adv. Mater. 2003, 15, 959-970.

B. Alberts, D. Bray, J. Lewis, Molecular Biology of the Cell. 5. Edition. Garland Science, New York 2008.

K. von Allmen, T. F. Nägler, T. Pettke, D. Hippler, E. Griesshaber, A. Logan, A. Eisenhauer, E. Samankassou, Chem. Geol. 2010, 269, 210-219

A. Al-Sawalmih, C. Li, S. Siegel, H. Fabritius, S. Yi, D. Raabe, P. Fratzl, O. Paris, Adv. Funct. Mater. 2008, 18, 3307-3314.

A. C. Auclair, M. M. Joachimski, C. Lecuyer, Chem. Geol. 2003, 202, 59-78.

F. Barthelat, H. D. Espinosa, Experim. Mech. 2007, 47, 311-324.

U. Brand, A. Logan, N. Hiller, J. Richardson, Chem. Geol. 2003, 198, 305-334.

N. Buening, Brachiopod shells: Recorders of the present and keys to the past. In: Brachiopods ancient and modern; A tribute to G. Arthur Cooper (Eds. S. J. Carlson and M. R. Sandy) Pal. Soc. Pap. 2001, 7, 117-145.

S. J. Carpenter, K. C. Lohmann, Geochim. Cosmochim. Acta 1992, 56, 1837-1849.

S. J. Carpenter, K. C. Lohmann, Geochim. Cosmochim. Acta 1995, 59, 3749-3764.

S. H. Chuang, J. Royal Soc. New Zealand, 1996, 26, 119-137.

J. D. Currey, J. D. Taylor, J. Zoology (London) 1974, 173, 395-406.

J. D. Currey, Proc. Royal Soc. London, 1977, 196, 443-463.

J. D. Currey, J. Experim. Biol. 1999, 202, 3285-3294.

J. D. Currey, Bones: Structure and Mechanics. Princeton Univ. Press, Princeton, New Jersey, 2006.

M. Cusack, J. H. Laing, K. Brown, D. Walton, Trends in Comparative Biochemistry and Physiology, 2000, 6, 47-56.

M. Cusack, Y. Dauphin, P. Chung, A. Pérez-Huerta, J.-P. Cuif, J. Struct. Biol. 2008, 164, 96-100.

P. Dalbeck, M. Cusack, Crystal Growth and Design, 2006, 6, 25582562.

H. Fabritius, C. Sachs, P. Romano, D. Raabe, Advanced Materials, 2009, 21, 391-400.

H. Fabritius, P. Walther, A. Ziegler, J. Struct. Biol. 2005, 150, 190-199.

H. Fabritius, A. Ziegler, J. Struct. Biol. 2005, 281-291, 2003.

P. Fratzl, R. Weinkamer, Progress in Mater. Sci. 2007, 52, 1263-1334.

D. Gaspard, F. Marin, N. Guichard, S. Morel, G. Alcaraz, G. Luquet, Earth and Environmental Sci. Trans. Royal Soc. Edinburgh 2008, 98, 415-424.

H. J. Gao, Internat. J. of Fracture 2006, 138, 101-137.

D. Gebauer, A. Völkel, H. Cölfen, Science 2008 322, 1819-1822.

A. Goetz, E. Griesshaber, W. W. Schmahl, R. D. Neuser, C. Lüter, E. M. Harper, M. Hühner, Eur. J. Mineral. 2009, 21, 303-315.

A. Goetz, D. R. Steinmetz, E. Griesshaber, S. Zaefferer, D. Raabe, K. Kelm, S. Irsen, A. Sehrbrock, W. W. Schmahl, Acta Biomaterialia 2011, 7, 2237-2243.

E. Griesshaber, W. W. Schmahl, R. D. Neuser, Th. Pettke, M. Blüm, J. Mutterlose, U. Brand, Amer. Mineral. 2007, 92, 722-734.

E. Griesshaber, K. Kelm, A. Sehrbrock, W. W. Schmahl, W. Mader, J. Mutterlose, U. Brand, Eur. J. Mineral. 2009, 21, 715-723.

E. Griesshaber, R. Neuser, W. W. Schmahl, Seminarios Soc. Espan. Mineralogia 2010, 7, 20-30.

E. Griesshaber, A. Goetz, L. Howard, A. Ball, S. Ruff, W. W. Schmahl, Bioinspired, Biomimetic and Nanobiomaterial 2012, 1 , $133-139$.

N. Hiller, Lethaia 1988, 21, 177-188.

A. P. Jackson, J. F. V. Vincent, R. M. Turner, Proc. Roy. Soc. London 1988, 234, 415-440. 
S. Kamat, X. Su, R. Ballarini, R., A. Heuer, Nature 2000, 405, $1036-1040$.

K. Katti, D. R. Katti, J. Tang, S. Pradhan, M. Sarikaya, J. Mater. Sci. 2005, 40, 1749-1755.

H. A. Lowenstam, J. Geol. 1961, 69, 241-260.

C. Lüter, Fossils and Strata, 2008, 54, 311-320.

F. C. Meldrum, H. Cölfen, Chemical Reviews, 2008, 108, 43324432.

C. Merkel, J. Deuschle, E. Griesshaber, S. Enders, E. Steinhauser, R. Hochleitner, U. Brand, W. W. Schmahl, J. Struct. Biol. 2009, $168,396-408$

A. Mucci, J. W. Morse, Geochim. et Cosmochim. Acta 1983, 47, 217-233.

K. Okumura, P. G. de Gennes, Eur. Phys. J. E Soft Matter 2001, 4, 121-127.

D. Parkinson, G. B. Curry, M. Cusack, A. E. Fallick, Chem. Geol. 2005, 219 193-235.

B. Pokroy, A. N. Fitch, F. Marin, M. Kapon, N. Adir, E. S. O. Zolotoyabko, J. Struct. Biol. 2006, 155, 96-103.

A. Rodriguez-Navarro, J. M. Garcia-Ruiz, Eur. J. Miner. 2000, 12, 609-614.

M. J. S. Rudwick, Geological Magazine 1959, 96, 1-24.

M. J. S. Rudwick, Living and Fossil Brachiopods. Hutchinson \& Co. LTD, London 1970.

M. Sarikaya, I. A. Aksay (eds.), Biomimetics, design and processing of materials. Woodbury, New York 1995.
W. W. Schmahl, W. W. E. Griesshaber, R. D. Neuser, A. Lenze, R. Job, U. Brand, Eur. J. Mineralog. 2004, 16, 693-697.

W. W. Schmahl, E. Griesshaber, R. D. Neuser, C. Merkel, J. Deuschle, A. Götz, K. Kelm, W. Mader, A. Sehrbrock, Mineralog. Mag. 2008, 72, 541-562.

W. W. Schmahl, K. Kelm, E. Griesshaber, A. Goetz, G. Jordan, D. Xu, C. Merkel, U. Brand, A. Logan, Seminarios de la Sociedad Espaniola de Mineralogia, 2010, 7, 5-21.

W. W. Schmahl, E. Griesshaber, K. Kelm, A. Ball, A. Goetz, D. Xu, L. Kreitmeier, G. Jordan, Z. Kristallogr. 2012, 227, 604-611.

J. Veizer, D. Ala, K. Azmy, Chem. Geol. 1999, 161, 59-88.

S. Weiner, L. Addadi, Annu. Rev. Mater. Res. 2011, 41, 21-40.

S. Weiner, W. Traub, W., H. D. Wagner, J. Struct. Biol. 1999, 126, $241-255$.

A. Williams, Spec. Pap. Pal., 1968, 2, 1-55.

A. Williams, S. J. Carlson, C. H. C. Brunton, Brachiopod classification. In: Williams, A. et al. Brachiopoda (revised), Treatise on Invertebrate Paleontology (Eds. Kaesler, R. L. et al.). Geological Society of America and the University of Kansas (Boulder, Colorado, Lawrence, Kansas) 2000.

A.-W. Xu, Y. Ma, H. Cölfen, J. Mater. Chem. 2007, 17, 415-449.

A.-W. Xu, M. Antonietti, S.-H. Yu, H. Cölfen, Advanced Material 2008, 20, 1333-1338.

A. Ziegler, H. Fabritius, M. Hagedorn, Micron 2005, 36, 137-153. 